\title{
On Bir Yaşındaki Çocukta Dev Seröz Kistadenoma Bağlı Over Torsiyonu: Bir Olgu Sunumu
}

\author{
Ovarian Torsion Due To Giant Ovarian Serous Cystadenoma \\ In An Eleven-Year Old Girl: A Case Report
}

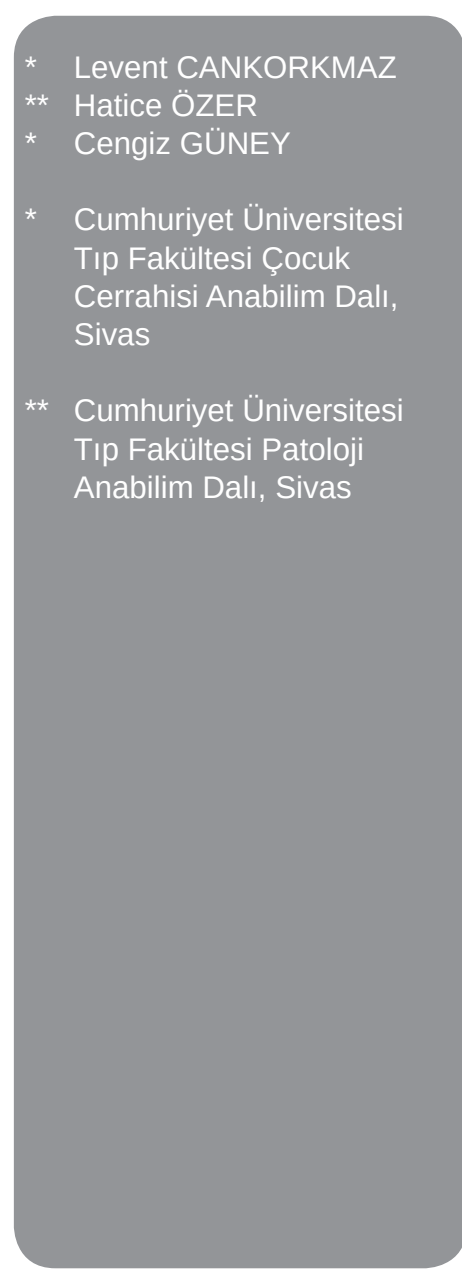

\section{Öz}

Adölesanlarda over torsiyonu sıklıkla overdeki benign ya da malign tümörlerin bir komplikasyonudur. Bu yazıda, akut karın ağrısı yakınmasıyla başvuran seröz kist adenoma bağlı sağ over torsiyonu tanısı konulan on bir yaşında kız olgu sunulmuştur. Adölesanlarda overin seröz kist adenomu ender olsa da over kitleleri ve torsiyonlarında epitelyal tümörlerin ayırıcı tanıda akılda tutulması, ameliyat sonrasında nüksler nedeniyle yakın takip yapılması açısından önemlidir. Çocukluk çağı over torsiyonlarında ameliyat sırasındaki makroskopik tanı ameliyatta bırakılacak over dokusunun planlaması ve izlemde önemlidir.

Anahtar Kelimeler: Adölesan, Over torsiyonu, Seröz kist adenom

\begin{abstract}
Ovarian torsion is frequently a complication of an underlying benign or malignant neoplasm in adolescent age group. In this paper, we present a case of eleven-year old girl with right ovarian torsion due to ovarian serous cystadenoma presented with acute abdominal pain. Although ovarian serous cystadenomas are rare in adolescent girls, it should be kept in mind in the differential diagnosis of ovarian torsion and a close follow-up is important after the surgery by reason of recurrences. Intraoperative macroscopic evaluation has great importance to protect the residual ovarian tissue and follow-up in childhood ovarian torsion.
\end{abstract}

Keywords: Adolescent, Ovarian torsion, Serous cystadenoma

\section{Giriş}

Over torsiyonları çocuklarda son derece enderdir, tüm over torsiyonlarının yaklaşık \%15'i infant ve çocuklarda görülür (1). Çocukluk yaş grubunda torsiyonlar sıklıkla overdeki bir patolojinin zemininde gelişmektedir. Büyük pediatrik serilerde, over torsiyonuna herhangi bir over patolojisinin eşlik etme oranı Cumhuriyet Üniversitesi Tıp Fakültesi Çocuk Cerrahisi AD. 58140 / SiVAS Tel: 05422506981 e-posta: Icankorkmaz@gmail.com Faks: 03462580032 \%51-84 arasındadır (1).

Over neoplazmları hücre tipine göre, epitalyal, stromal ve germ hücreli olmak üzere üç gruba ayrılır (2). Çocuklarda, yüzey epitelinden kaynaklanan over tümörleri (seröz ve müsinöz kistadenomlar vs.) enderdir. 
Yazımızda, çocuklarda ender olan seröz kistadenoma bağlı over torsiyonu gelişen bir kız çocuğu sunulmuştur.

\section{Olgu}

On bir yaşında kız çocuğu 24 saattir devam eden yaygın karın ağrısı ve kusma yakınmasıyla acil servise başvurdu. Öyküsünde, yaklaşık altı aydır aralıklı karın ağrısı ve karın şişliği yakınması olduğu öğrenildi. Fizik bakısında, batın her iki alt kadranda hassasiyet ve suprapubik bölgede mobil bir kitle saptandı. Defans ve rebound yoktu. Hastanın ultrasonografisi; boyutları 44×25 mm olan sol overde çok sayıda anekoik kist, Douglas boşluğunda minimal sıvı, sağ adneksiyel bölgeden başlayıp Douglas'a uzanan, içerisinde çok sayıda kistik ve solid alanlar içeren, $85 \times 40 \mathrm{~mm}$ boyutlarında kitle ve doppler ultrasonografide kitle içerisinde kan akımı izlenmedi, şeklinde raporlandı.

Hasta bu bulgularla over kitlesi ve torsiyonu ön tanılarıyla acil olarak ameliyata alındı. Yapılan eksplorasyonda, sağ torsiyone overde kitle ve iskemik renk değişiklikleri saptandı. Sol over ise, benign izlenimi veren multipl kistler dışında normal olarak değerlendirildi. Acil koşullarda frozen biyopsi yapılamadığından, kitlenin büyüklüğü, solid ve kistik yapılar içermesi malignensi potansiyelinin yüksek olduğunu düşündürdüğünden salpingooferektomi kararı verildi.

Kitlenin makroskopik incelemesinde; 1550 gr ağırlığında, 22x13x9 cm ölçülerinde koyu şarabi renkli kistik yapı ve üzerinde $8 \mathrm{~cm}$ uzunluğunda, $1 \mathrm{~cm}$ çapında tuba uterinadan oluşan, sağ salpingo-ooferektomi materyali. Kitleye kesit yapıldığında, içerisinden seröz
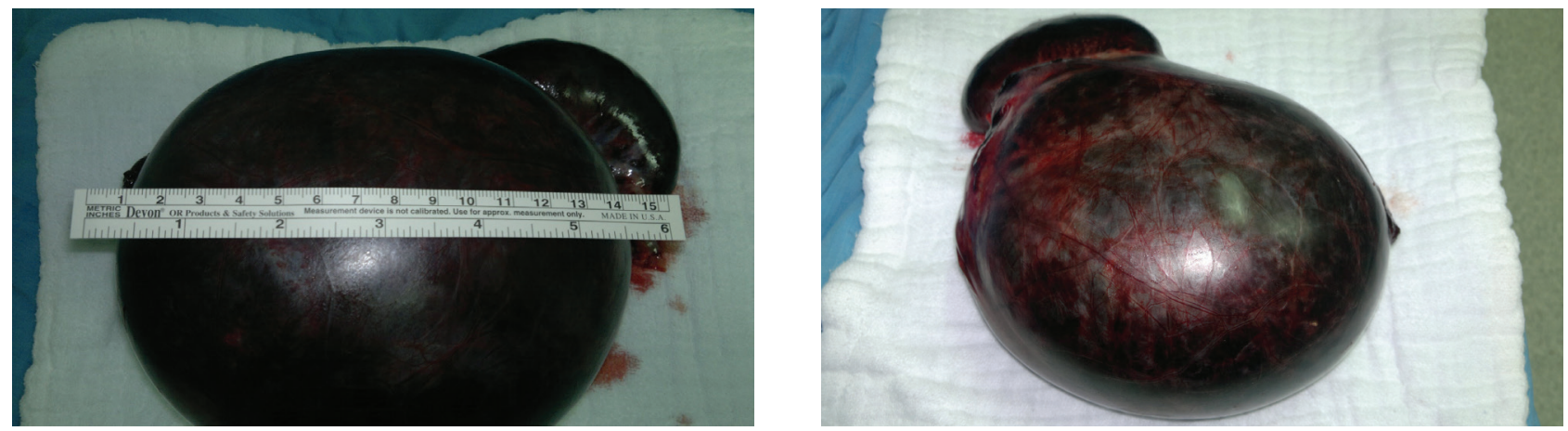

kıvamlı gri-kahverengi sıvı boşaltıldı. İç yüzü düzgün kanamalı görünümde ve duvar kalınlığı 0,3-0,4 cm idi. Ayrıca kistik yapının bitişiğinde 8x4x4 cm'lik kanamaIı, ödemli görünümde over dokusu saptandı (Resim 1 ve 2).

Histopatolojik incelemesinde; geniş kanama alanları, primordial follikül içeren over stroması komşuluğunda yüksek kolumnar, silyalı seröz epitel ile döşeli kistik yapı izlendi (Resim 3-5).

Bu histopatolojik bulgularla hastaya seröz kistadenom tanısı konuldu. Hasta ameliyattan sonra izleme alındı. İki yıllık izleminde bir patoloji saptanmadı.

\section{Tartışma ve Sonuç}

Puberte öncesi over torsiyonlarına genellikle overin nonneoplastik lezyonları, benign ve malign tümörleri eşlik eder (3). Yaşamın birinci dekadında over tümörleri enderdir. Çocuklardaki over tümörlerinin \%50'den fazlası germ hücre kaynaklı olup, çoğu benign teratomdur. Epitelyal tümörler tüm yaş gruplarında primer over neoplazmlarının \%70-85'ini oluştursa da çocuklarda bu oran \%14 civarındadır. Özellikle prepubertal yaş grubunda enderdir. Yüzey epitel hücresi orijinli tümörler daha azdır ve en sık olanı seröz kistadenomdur (4).

Çocuklarda fertilizasyon kapasitesinin korunması ve normal gelişim için overlerin nonneoplastik lezyonları, benign tümörleri ve torsiyonlarının erken tanısı ve cerrahi yöntemin seçimi yetişkin hastalara göre daha önemlidir (5). konjesyone damarlar ve belirgin ödem ile çok sayıda

Resim 1-2: Torsiyone over dokusu ve eşlik eden Kist. 

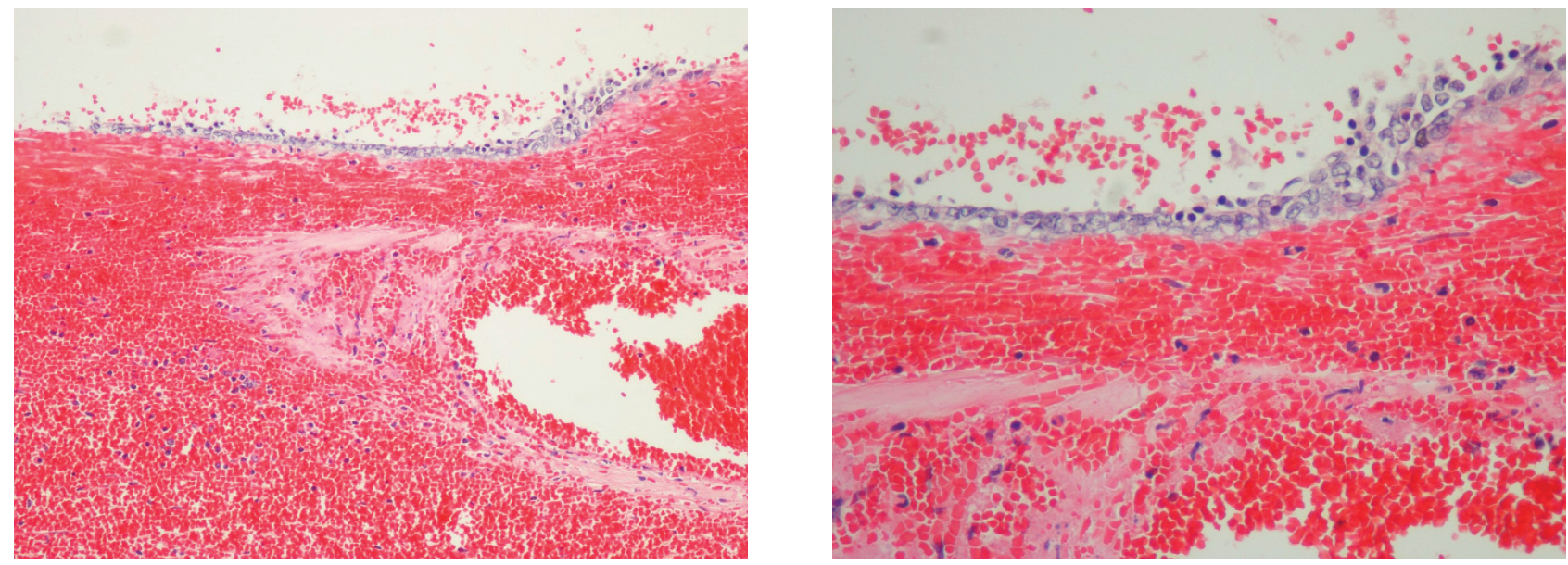

Resim 3-4: Kisti döşeyen tek sıralı seröz epitel ve epitel altında kanamalı stroma (H-E; X100, X200)
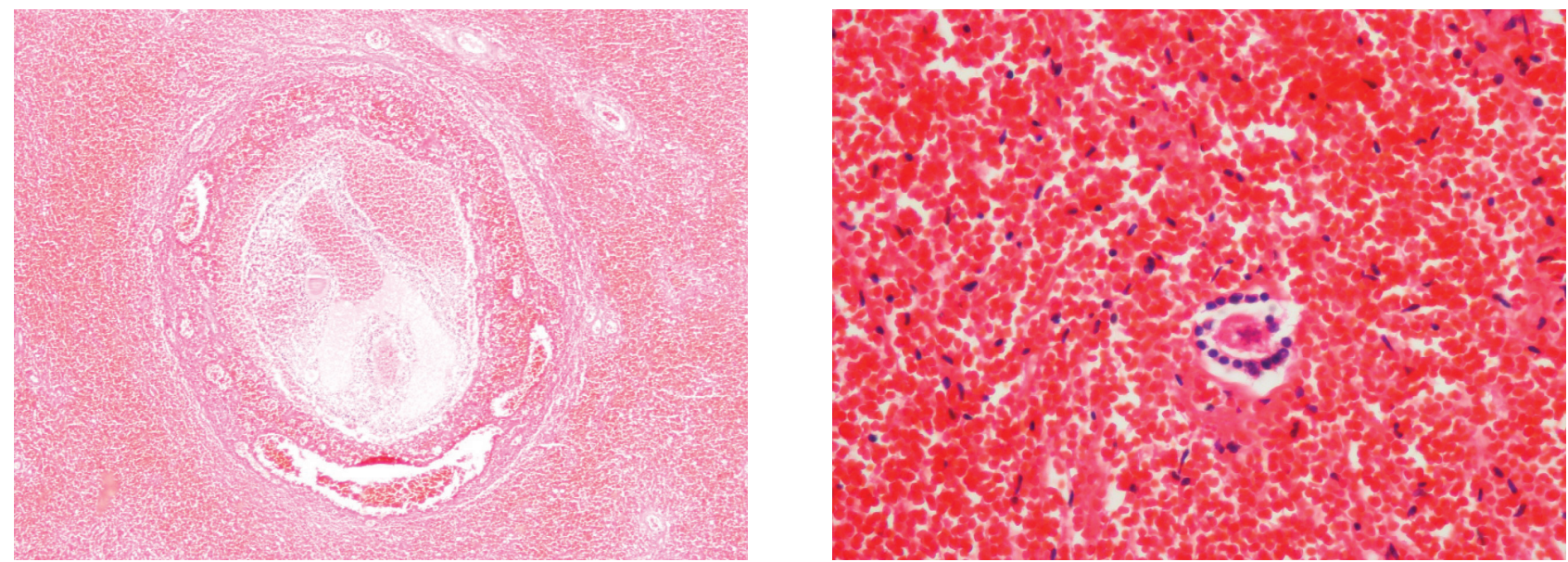

Resim 5-6: Kist dışı over stromasında izlenen tersiyer ve primordial folikül yapıları ile torsiyona bağlı değişiklikler (H-E; X100, X200)

Olgumuzun ultrasonografi bulguları ve fizik bakıda ele gelen kitlenin büyüklüğü nedeniyle, açık cerrahiye karar verildi. Torsiyone overlerin ameliyattaki infarktla uyumlu olan görünümleriyle, overdeki mikroskopik nekroz oranı arasında bir bağıntı olmaması, torsiyone overlerde nekrotik olmayan dokuların bulunabilmesi nedeniyle çocuklarda over torsiyonunda salpingoofereketomi yerine, morbidite riski minimal olan laparoskopik detorsiyon tercih edilmektedir $(1,4)$. Tüm bu yaklaşımlara rağmen, over tümörlerinde laparoskopik yaklaşım hem tedavide hem de overin ve fertilizasyonun korunmasında etkin bir yöntem olsa da, karın içi büyük kitleler laparoskopinin risk oluşturan dezavan- tajı olarak görülmektedir (6). Seröz ve müsinöz kistadenomlarda, laparoskopik yaklaşımla kitleyi karın dışına almak için aspire edilmemesi gerekliliği ve kitlenin karın içinde açılması durumunda evre I tümörün evre III olabileceği de belirtildiğinden, yaklaşımımızın uygun olduğunu düşünmekteyiz (6). Bunun yanında laparoskopik cerrahi, malignitenin preoperatif olarak dışlanabildiği adneksiyal kitlelerin yönetiminde altın standart olarak kabul edilmiştir $(7,8)$.

Konservatif cerrahi kararı verilen olgularda rezidüel over dokusunda, radyolojik olarak ve ameliyatta saptanamayan mikroskopik boyuttaki malign neoplazmlar gözden kaçabilmektedir. Tam rezeksiyon yapılmadı- 
ğında risk ortadan kalkmayacağından, hastanın cerrahi sonrası yakın izlemi gerekir (4).

Çocuklarda seröz kistadenomların malignleşme potansiyeline rağmen tedavide, normal olan over dokusunu koruyarak, lezyon ve kistik over dokusunun rezeksiyonu, kist aspirasyonu gibi konservatif cerrahi, total over rezeksiyonunun ise malignite şüphesi güçlü olgularda tercih edildiği belirtilmektedir $(4,9)$. Olgumuzun öyküsünde uzun süreli bir karın ağrısı yakınmasını izleyen torsiyon olgusu olması, torsiyona eşlik eden kitlenin boyutu ve kitlenin solid ve kistik kompanentlere sahip olması nedeniyle malignensi potansiyeline sahip olabileceği düşünülmüştür.

Sonuç olarak, çocuk yaş grubundaki over torsiyonlarında ameliyat sırasında makroskopik tanı ve tedavinin seçimi yetişkin hastalara göre daha güçtür Makroskopik ön tanı, yapılacak cerrahi işlem ve bırakılacak over dokusunun planlanmasında yol göstericidir. Çocuklardaki over torsiyonuna neden olan kitlelerin ayırıcı tanısında ender de olsa overin epitelyal tümörlerinin akılda tutulması, bu olguların ameliyatın planlaması ve ameliyat sonrası izleminde önemlidir.

\section{Kaynaklar}

1. Cass DL. Ovarian torsion. Semin Pediatr Surg. 2005; 14(2):86-92.

2. Sujatha VV, Babu SC. Giant ovarian serous cystadenoma in a postmenopausal woman:a case report. Cases J. 2009; 2: 7875.

3. Rosai J. Rosai and Ackerman's Surgical Pathology, 9th ed., Springer, New York, 2004, pp.1639, 1659-1661.

4. Şahin D, Çetiner H, Gence A, Celayir A. Yedi yaşındaki çocukta sağ ovaryumda torsiyon, sol ovaryumda seröz kistadenom: Olgu sunumu. Türk Patoloji Dergisi 2008; 24(2): 125-129.

5. Tseng D, Curran TJ, Silen ML. Minimally invasive management of the prenatally torsed ovarian cyst. J Pediatr Surg. 2002; 37(10): 1467-1469.

6. Günaydın M. Over kitlelerine laparoskopik yaklaşım. Çocuk Cerrahisi Dergisi 2016; 30 (Ek sayı 3): 263-272.

7. Mayer JP, Bettolli M, Kolberg-Schwerdt A, Lempe M, Schlesinger F, Hayek I, et al. Laparoscopic approach to ovarian mass in children and adolescents: already a standard in therapy. J Laparoendosc Adv Surg Tech A. 2009; 19 (Suppl. 1): S111-115.
8. Seckin B, Ozdener T, Tapisiz OL, Batioğlu S. Laparoscopic treatment of ovarian cysts in adolescents and young adults. J Pediatr Adolesc Gynecol 2011; 24: 300-303.

9. Darrell L. Cass, Edith Hawkins, Mary L. Brandt, Murali Chintagumpala, Robert S. Bloss, Alan L. Milewicz, et al. Surgery for ovarian masses in infants, children, and adolescents: 102 consecutive patients treated in a 15-year period. Pediatr Surg. 2001; 36: 693-699. 